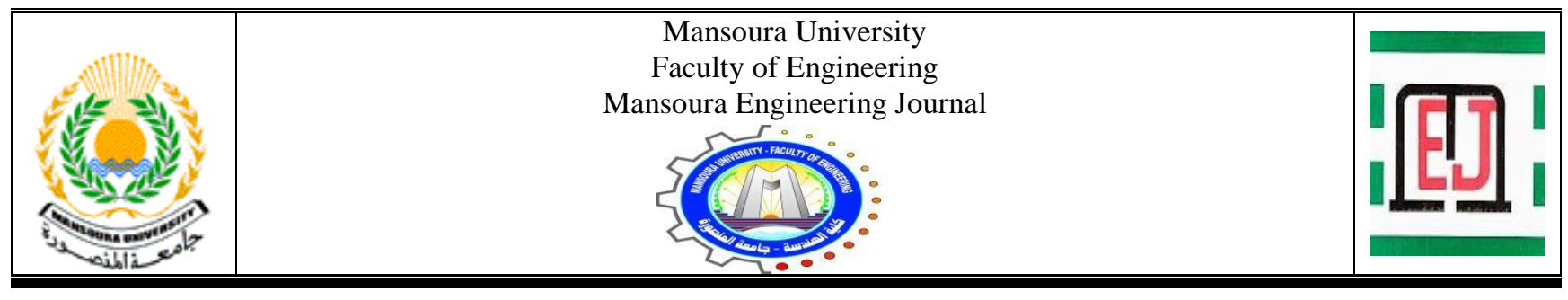

\title{
Reactive Power Planning and Total Transfer Capability Enhancement using Facts and Capacitor Banks
}

\author{
Mohammad I. Basha*, Abdelfattah A. Eladl and Azza A. ElDesouky
}

\begin{tabular}{|lr|}
\hline KEYWORDS: & \\
Reactive & Power \\
Planning, & FACTS \\
devices, & Capacitor \\
Banks, & MOGA \\
Optimization, & Total \\
Transfer Capacity & \\
& \\
& \\
& \\
\end{tabular}

Abstract-In view of the continuous annual increase in demand, reactive
power planning (RPP) is considered one of the most significant problems to
address a major challenge of the secure power system operation. In this paper, a
multi-objective genetic algorithm (MOGA) for RPP is proposed, with the goals
of cost minimization of power losses, new reactive power (VAR) sources, and
maximizing the Total Transfer Capacity (TTC). Different optimization factors
are taken into account, including generator voltages, transformer tap changers,
and various operating constraints. A fuzzy min-max approach is used to identify
the optimum compromise option. Studies are being conducted to compare
capacitor banks, flexible ac transmission systems (FACTS), or both as a new
VAR support source to improve the system performance. Moreover, the optimal
allocations of switchable VAR sources are not determined in advance; instead,
they are treated as control variables to improve the techno-economic operation
of the network. The effectiveness of the proposed algorithm is examined on the
IEEE 30-bus test system where felicitous results have been acquired. From the
results, the total annual cost is decreased from $3.671 \times 10^{6} \$$ before adding new
VAR sources to a range between $2.02 \times 10^{6}$ and $2.486 \times 10^{6} \$$ depending on the
selected type of VAR source. While the transfer capacity is increased from
$458.37 M W$ to a range between 483.084 and $539.055 \mathrm{MW}$.

Received: (31 July, 2021) - Revised: (19 August, 2021) - Accepted: (24 August, 2021)

*Corresponding Author: Mohammad I. Basha, Researcher (MSc) at Electrical Engineering Department (Port-Said University); Operation Engineer, East Delta for Electricity Production Company (EDEPCo), Damietta, Egypt (e-mail: mohammadbasha200@gmail.com).

Abdelfattah A. Eladl, Associate Professor at Electrical Engineering Department, Mansoura University, El-Mansoura, Egypt (e-mail: eladle7@mans.edu.eg).

Azza A. ElDesouky, Professor at Electrical Engineering Department, Port-Said University, Port-Said, Egypt (e-mail: azzaeldesouky@yahoo.com).

\section{NOTATION}

A. Sets of indices

\begin{tabular}{l||l}
\hline A. Sets of indices \\
\hline$N_{b}$ & Total number of buses \\
\hline$N_{\text {cap }}$ & Number of a possible installed capacitor bank \\
\hline$N_{d}$ & Number of load level duration \\
\hline$N_{g}$ & Number of generators \\
\hline$N_{L}$ & Number of transmission lines \\
\hline$N_{S V C}$ & Number of possible installed SVC devices \\
\hline$N_{T}$ & Number of installed transformers \\
\hline$N_{T C S C}$ & Number of possible installed TCSC devices \\
\hline
\end{tabular}

\section{B. Constants and parameters}

\begin{tabular}{l||l}
\hline$B_{i j}$ & Transmission line susceptance between bus $i$ and bus $j$ (p.u) \\
\hline$C_{c}$ & The per-unit cost of the capacitor bank (\$/MVAR) \\
\hline$C_{F}$ & The fixed installation cost of capacitor bank in (\$) \\
\hline$G_{i j}$ & Transmission line conductance between bus $i$ and bus $j$ (p.u) \\
\hline$h_{l}$ & Per-unit energy cost (\$/MWh) \\
\hline$i r$ & The interest rate for VAR devices (\%) \\
\hline \multicolumn{2}{|c}{ continued on the next page }
\end{tabular}




\begin{tabular}{|c|c|}
\hline \multicolumn{2}{|c|}{ NOTATION: continued } \\
\hline$L T$ & The lifetime of VAR devices (years) \\
\hline$R_{i j}$ & Transmission line resistance between bus $i$ and bus $j$ (p.u \\
\hline$X_{i j}$ & Transmission line reactance between bus $i$ and bus $j$ (p.u) \\
\hline \multicolumn{2}{|c|}{ C. Variables } \\
\hline$Q_{c . i}$ & $\begin{array}{l}\text { Operating range of newly installed capacitor bank at bus } i \\
\text { (MVAR) }\end{array}$ \\
\hline$B_{c, i}$ & Susceptance of newly installed capacitor bank at bus $i$ (p.u) \\
\hline$V_{i} \cdot V_{j}$ & Voltage magnitude of bus $i$ and $j$ respectively (p.u) \\
\hline$Q_{s v c . i}$ & $\begin{array}{l}\text { Reactive power injections at bus } i \text { by newly installed SVC } \\
\text { device (MVAR) }\end{array}$ \\
\hline$\beta_{s v c . i}$ & Susceptance of newly installed SVC device at bus $i$ (p.u) \\
\hline$X_{T C S C . l}$ & The reactance of new installed TCSC device at line $l$ (p.u) \\
\hline$\delta_{i j}$ & The phase angle between bus $i$ and $j$ (rad.) \\
\hline$C_{l}$ & The cost of active power losses of the power system (\$) \\
\hline$W_{\text {Cap }, i}$ & Cost of the newly installed capacitor bank (\$) \\
\hline$W_{s v c, i}$ & Cost of installed SVC devices at bus $i$ (\$/MVAR) \\
\hline$W_{T C S C, l}$ & Cost of installed TCSC devices at line $l$ (\$/MVAR) \\
\hline$d_{l}$ & Duration of load level, L (Hour) \\
\hline$V C_{V A R}$ & Installing cost of added VAR sources (\$) \\
\hline$T V C_{V A R}$ & Annual installing cost of new installed VAR sources (\$) \\
\hline$P_{g i}, Q_{g i}$ & Active and reactive power generated at bus $i$ (MW/MVAR) \\
\hline$P_{l i}, Q_{l i}$ & Active and reactive load power at bus $j$ (MW/MVAR) \\
\hline$P_{\text {loss }, l}$ & Network active power loss during the period $l(\mathrm{MW})$ \\
\hline$Q_{o i}$ & $\begin{array}{l}\text { Inductive or capacitive power of exiting VAR source installed } \\
\text { at bus } i \text { (MVAR) }\end{array}$ \\
\hline
\end{tabular}

\section{INTRODUCTION}

$\mathrm{O}$ ne of the most difficult aspects of contemporary power system operation is meeting ever-increasing load demand while ensuring dependable power supply to consumers and keeping voltage within acceptable limits for high-quality customer service. The reactive power balance of a power system and the voltages have an equal and strong interaction. A reactive power balance will always exist intrinsically, but with unacceptably voltage limits if the balance is not correct. High voltages result from an excess of generated reactive power than consumed in a given region, whereas low voltages result from a shortage [1]. As a result, one of the most essential operational responsibilities for electric power utilities is to maintain an acceptable voltage range for high-quality customer service.

Voltage breakdowns and subsequent major power outages may result from insufficient reactive power support. As a result, adequate controlled reactive power resources are required to ensure the dependable functioning of electric power networks by keeping load bus voltages within acceptable bounds. Although the August 2003 blackout in the US and Canada was not caused by a voltage collapse, the USCanada Power System Outage Task Force's final report said that "insufficient reactive power was an issue in the blackout" [2].

Reactive power planning (RPP) is an issue that involves determining all categories of reactive power controllable variables, such as generator reactive power outputs, transformer tap ratios, allocate new reactive power (VAR) sources, and so on, in order to minimize transmission losses or other effective objective functions while agreeing to meet a number of defined operating constraints. On the other hand, newly installed VAR sources controllers can improve the efficiency of power transfer capability. These sources could be used for enhancing system controllability resulted in the total transfer capacity (TTC) enhancement also [3]. Improving current electricity power production systems is far more reasonable than constructing new power plants, electrical power transmission, and distribution lines, which may take several years in addition to the high cost of installation and the difficulties of pollution control. Also, it may be claimed that system congestion will be decreased, resulting in increased power system security. The transmission system will be more lucrative if current transmission assets are used to their full potential.

For years, a number of traditional approaches have been widely utilized to tackle the RPP problem. Among these methods: Successive linear programming method is presented in [4]. Mixed-integer non-linear programming is presented in [5]. Branch-and-bound method is presented in [6]. However, because the RPP issue is non-differential, non-linear, and nonconvex, traditional techniques may fail to discover the global optimal solution and instead converge to a local optimum. As a result, it becomes important to design efficient optimization approaches to deal with the problems that traditional methods have. To solve the drawbacks of previous approaches, intelligent searches and fuzzy set applications have been used to solve the RPP problem.

Evolutionary programming (EP)is proposed in [7] to solve the RPP problem, particle swarm optimization (PSO) is applied in [8], differential evolution (DE) is presented in [9] and [10], Ant colony optimization algorithm is presented in [11], gravitational search algorithm (GSA) is using to solve RPP problem with flexible ac transmission systems (FACTS) in [12], random drift PSO in [13], and fractional-order darwinian PSO is presented in [14]. In [3] PSO algorithm is presented to maximize the power transfer capability of power transactions between generators and loads in power systems without violating system constraints, genetic algorithm (GA) is proposed in [15], the static synchronous series compensator is used in [16], EP is proposed to determine the optimal allocation of FACTS devices in [17], Cat swarm optimization is applied in [18], hybrid of tabu search and simulated annealing in [19], and different methods of FACTS placements for maximizing the transfer power is applied in [20]. Table I categorizes the evaluated literature and highlights the new aspects of the proposed work in comparison to previous research efforts.

In the present work, a multi-objective genetic algorithm (MOGA) is used to solve the RPP problem. The first objective is to minimize the cost of losses and the cost of new VAR source investment. The second objective is to maximize the TTC. The paper relied on more than one method to 
compensate for the lack of reactive power in the power system. For example, capacitors were relied upon only as a VAR source, once again the FACTS were relied upon, and finally, a hybrid assortment of capacitor bank and FACTS is used. A comparison between using each method of them was discussed. In addition, in this paper, the new optimal VAR sources allocations are considered as control variables and are resolved via GA. The IEEE 30-bus system is used to examine the accuracy of the proposed approach.

TABLE I.

COMPARISON TO PREVIOUS RESEARCH EFFORTS

\begin{tabular}{|c|c|c|c|c|c|c|c|c|c|}
\hline \multirow{2}{*}{ Ref. } & \multirow{2}{*}{ Year } & \multirow{2}{*}{$\begin{array}{c}\text { Optimization } \\
\text { algorithm }\end{array}$} & \multirow{2}{*}{$\begin{array}{l}\text { Min. } \\
\text { Losses }\end{array}$} & \multirow{2}{*}{$\begin{array}{l}\text { Min. VAR } \\
\text { Cost }\end{array}$} & \multirow{2}{*}{$\begin{array}{l}\text { Max. } \\
\text { TTC }\end{array}$} & \multicolumn{2}{|c|}{ VAR sources } & \multirow{2}{*}{ multi objective } & \multirow{2}{*}{$\begin{array}{c}\text { Transformer } \\
\text { ratio }\end{array}$} \\
\hline & & & & & & Capacitor's bank & FACTS & & \\
\hline [3] & 2014 & PSO & $x$ & $x$ & $\checkmark$ & $x$ & $\checkmark$ & $x$ & $x$ \\
\hline [8] & 2016 & Simple PSO & $\checkmark$ & $\checkmark$ & $x$ & $\checkmark$ & $x$ & $x$ & $\checkmark$ \\
\hline [12] & 2015 & GSA & $\checkmark$ & $\checkmark$ & $x$ & $x$ & $\checkmark$ & $x$ & $\checkmark$ \\
\hline [13] & 2020 & Random drift PSO & $\checkmark$ & $x$ & $x$ & $\checkmark$ & $x$ & $x$ & $x$ \\
\hline [14] & 2021 & $\begin{array}{l}\text { fractional order } \\
\text { Darwinian PSO }\end{array}$ & $\checkmark$ & $\checkmark$ & $x$ & $x$ & $r$ & $x$ & $\checkmark$ \\
\hline$[16]$ & 2006 & - & $x$ & $x$ & $\checkmark$ & $x$ & $\checkmark$ & $x$ & $x$ \\
\hline [17] & 2005 & EP & $x$ & $x$ & $\checkmark$ & $x$ & $\checkmark$ & $x$ & $x$ \\
\hline$[18]$ & 2015 & Cat Swarm Optimization & $x$ & $x$ & $\checkmark$ & $x$ & $\checkmark$ & $x$ & $x$ \\
\hline [19] & 2019 & $\begin{array}{l}\text { Tabu search and } \\
\text { simulated annealing }\end{array}$ & $x$ & $x$ & $r$ & $x$ & $r$ & $x$ & $x$ \\
\hline$[20]$ & 2020 & - & $\checkmark$ & $x$ & $\checkmark$ & $x$ & $\checkmark$ & $x$ & $x$ \\
\hline $\begin{array}{l}\text { This } \\
\text { Work }\end{array}$ & 2021 & MOGA & $\checkmark$ & $r$ & $r$ & $\checkmark$ & $r$ & $r$ & $r$ \\
\hline
\end{tabular}

The main contributions of the present work are:

1. A MOGA application to handle the RPP problem for minimizing the costs of power loss and installing VAR sources, as well as maximizing the TTC.

2. A variety of VAR sources are provided, each with a thorough model.

3. Rather than putting new VAR sources on the weakest lines or buses, the locations of new VAR sources are utilized as control variables to determine the best allocation.

The rest of the paper is organized as follows: the modeling of the new VAR sources is described in Section II. Section III describes the multi-objective RRP problem formulation. The multi-objective RPP solution algorithm proposed for solving the RPP is presented in section IV. Section V provides test results and discussion. Section VI conclusions are presented.

\section{MOdeling OF NEW VAR SOURCE}

The model of several VAR sources is provided in this section. Two techniques may be used to simulate VAR sources for static applications: (i) impedance insertion model (IIM), and (ii) power injection model (PIM) [21].

\section{A. Modeling of capacitor bank}

In the power system, shunt capacitors were used as a VAR source. The shunt capacitors draw a leading current to compensate for the load's lagging current. In addition to fixed capacitor banks, variable capacitor banks are also available. Switched capacitors are used to create a variable capacitor bank [22]. Capacitor banks are moved into or out of the system depending on the overall VAR required. Relays and circuit breakers are commonly used to switch things on and off. Mechanical switches and relays, on the other hand, have the disadvantage of being slow and unreliable. They also produce large inrush currents and need frequent maintenance [22]. The obtained MVAR from the capacitor bank source is in stages due to the method of altering the value of variable capacitors bank, and VAR source size is used as a discrete variable rather than a continuously variable. The modelling of a capacitor bank is shown in Fig. 1. The injected reactive power at bus $i$ is:

$$
Q_{c . i}=V_{i}^{2} B_{c, i}
$$

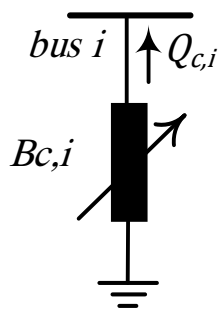

Fig. 1. capacitor bank model

\section{B. Modeling of FACTS devises}

The electromechanical device was utilized to address the VAR compensation problem in a couple of years. The equipment in question was a bank of switching inductors or capacitors, as well as a phase-shifting transformer. However, owing to the issues with this technology, all of this equipment is not dependable or efficient enough [22]. They're not only 
sluggish, but they're also difficult to switched repeatedly since they wear out rapidly [23]. FACTS devices are utilized as a result of advancements in semiconductor technology. It provides up new possibilities for power control, loss reduction, and improving the unstable capacity of existing transmission lines [23]. There are several different forms of FACTS that may be used in a power system. static var compensator (SVC) and thyristor-controlled series compensators (TCSC) are two techniques that might be used to achieve our goal. For reactive power support and voltage stability augmentation, these devices have been widely utilized in electric power systems. They're also selected for their quick control responses and potential to boost loadability $[21,24]$.

\section{- Modeling of SVC}

SVC is mainly composed of typical reactive power shunt elements (reactors and capacitors) that are controlled to generate a reactive power in a fast and variable manner. The MVAR obtained from the SVC device is continuously changing, so the VAR source size is employed as a continuously variable. The SVC is modelled as a shunt variable susceptance injecting reactive power at the selected bus [22]. The fundamental structure of SVC is shown in Fig. 2(a). SVC may adjust bus voltage by absorbing or injecting reactive power and can offer fast-acting reactive support in power systems. The modelling of SVC is shown in Fig. 2(b). The injected reactive power at bus $i$ is:

$$
Q_{s v c, i}=B_{s v c, i} V_{i}^{2}
$$

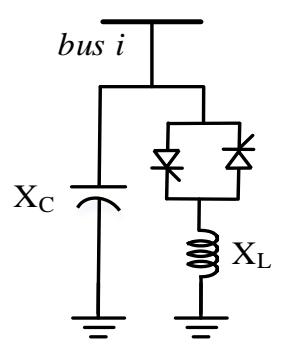

(a)

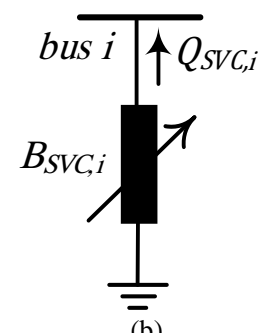

$\overline{(b)}$

(a) basic structure

(b) power injection model

\section{- Modeling of TCSC}

Many benefits for a power system may be accomplished using a TCSC, including controlling power flow in the line, dampening power oscillations, and increasing voltage stability. A TCSC is a capacitive reactance compensator, it depends on a series capacitor bank and a thyristor-controlled reactor to generate a smoothly changing series capacitive reactance [25].

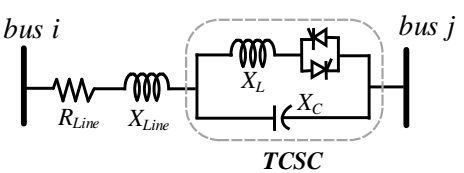

(a)

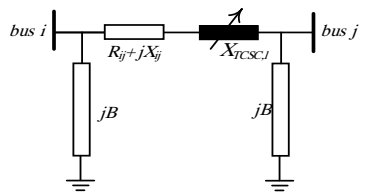

(b)

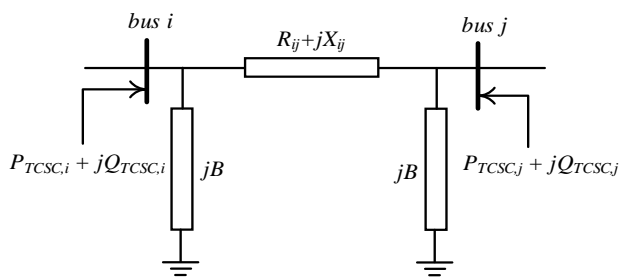

(c)

Fig. 3. Thyristor series compensator TCSC (a) basic structure $\begin{array}{ll}\text { (b) steady-state model } & \text { (c) power injection model }\end{array}$

The TCSC is one of the most significant and well-known FACTS devices, having been in use for many years to maximize power transmission and improve system stability. A schematic depiction of a TCSC linked in a transmission line between bus $i$ and $j$ of a power system is shown in Fig. 3(a). The idea of TCSC in voltage stability enhancement is to modify the TCSC reactance to control the transmission line impedance.

Fig. 3(b) shows the modeling of TCSC for steady-state applications. Where $Z_{i j}$ and $j B_{s h}$ represented the series and shunt impedance of the transmission line, respectively and $-X_{c}$ represents the TCSC capacitive reactance.

As in Fig. 3(c) the effect of TCSC is reflected as power injections at terminal buses of $i$ and $j$ between which the TCSC is located. The TCSC in the power injection model is represented by four injected powers as follows [26]:

$$
\begin{aligned}
P_{T C S C, i} & =\left|V_{i}\right|^{2} \Delta G_{i j}-\left|V_{i}\right|\left|V_{j}\right|\left[\Delta G_{i j} \cos \left(\delta_{i j}\right)+\Delta B_{i j} \sin \left(\delta_{i j}\right)\right] \\
Q_{T C S C, i} & =-\left|V_{i}\right|^{2} \Delta B_{i j}-\left|V_{i}\right|\left|V_{j}\right|\left[\Delta G_{i j} \sin \left(\delta_{i j}\right)-\Delta B_{i j} \cos \left(\delta_{i j}\right)\right] \\
P_{T C S C, j} & =\left|V_{j}\right|^{2} \Delta G_{i j}-\left|V_{i}\right|\left|V_{j}\right|\left[\Delta G_{i j} \cos \left(\delta_{i j}\right)-\Delta B_{i j} \sin \left(\delta_{i j}\right)\right] \\
Q_{T C S C, j} & =-\left|V_{i}\right|^{2} \Delta B_{i j}+\left|V_{i}\right|\left|V_{j}\right|\left[\Delta G_{i j} \sin \left(\delta_{i j}\right)+\Delta B_{i j} \cos \left(\delta_{i j}\right)\right]
\end{aligned}
$$

where $P_{T C S C, i}, Q_{T C S C, i}, P_{T C S C, j}$ and $Q_{T C S C, j}$ are power injections (positive or negative) due to installing the TCSC in branch $i-$ $j$. Also, $\Delta G_{i j}$ and $\Delta B_{i j}$ depend on TCSC reactance and are given as [26]:

$$
\Delta G_{i j}=\frac{-X_{T C S C} R_{i j}\left(X_{T C S C}-2 X_{i j}\right)}{\left(R_{i j}^{2}+X_{i j}^{2}\right)\left[R_{i j}^{2}+\left(X_{i j}-X_{T C S C}\right)^{2}\right]}
$$

$$
=\frac{X_{T C S C}\left(R_{i j}^{2}-X_{i j}^{2}+X_{T C S C} X_{i j}\right)}{\left(R_{i j}^{2}+X_{i j}^{2}\right)\left[R_{i j}^{2}+\left(X_{i j}-X_{T C S C}\right)^{2}\right]}
$$

\section{Problem formulation}

The RPP problem is a mathematical formulation that may be summarized as an attempt to find the best solution for an objective function using a collection of controllable variables.

\section{A. Objective function}

The RPP problem deals with a number of distinct objective functions. These are as the following: 


\section{A.1. Active power losses cost}

Minimization of active power losses cost $\left(C_{l}\right)$ of the power system is the first objective and it is calculated as [27]:

$$
\begin{aligned}
C_{l}= & \sum_{i \in N_{d}} h_{l} d_{l} P_{\text {loss }, i} \\
P_{\text {loss }, i}= & \sum_{j \in N_{L}} G_{i j}\left[V_{i}^{2}+V_{j}^{2}-2 V_{i} V_{j} \cos \left(\delta_{i j}\right)\right]
\end{aligned}
$$

\section{A.2. VAR cost}

Minimization of the new VAR sources investment costs $\left(V C_{V A R}\right)$ is the second objective in the RPP problem and it is formulated as:

$$
\begin{gathered}
V C_{V A R}=\sum_{i \in N_{S V C} C} W_{S v c, i} \times Q_{S V C, i}+\sum_{l \in N_{T C S C}} W_{T C S C, l} \times Q_{T C S C, l} \\
+\sum_{i \in N_{\text {cap }}} W_{C a p, i}
\end{gathered}
$$

Eq. (11) consisting of three parts represent the costs of the SVC, TCSC, and capacitor banks [21], respectively where;

$$
\begin{aligned}
& W_{S v C}=0.0003 Q_{S V C}^{2}-0.3051 Q_{S V C}+127.38 \\
& W_{T C S C}=0.0015 Q_{T C S C}^{2}-0.7131 Q_{T C S C}+153.57 \\
& W_{C a p}=C_{F}+C_{c} Q_{c}
\end{aligned}
$$

where $\mathrm{C}_{\mathrm{F}}=1000 \$$, and $\mathrm{C}_{\mathrm{c}}=3 \times 10^{4} \$$ /MVAR [27]. by:

As [21] the annual installing cost of VAR sources is given

$$
T V C_{V A R}=V C_{V A R} \frac{i r(1+i r)^{L T}}{(1+i r)^{L T}-1}
$$

\section{A.3. Enhancement of TCC}

To identify the best allocation of VAR sources for TTC enhancement, the third objective function is stated as maximizing of $\left(P_{m}\right)$ value, which is computed as the sum of real power loads in the load buses at maximum power transfer [3].

$$
P_{m}=\sum_{i=1}^{N_{b}} P_{l i}
$$

\section{B. Constraint}

Many constraints must be met in order for the system to operate in a stable and dependable manner. Furthermore, these constraints ensure that the best solution obtained is practicable for power system operation. There are two types of constraints: equality and inequality constraints. Later, we'll look at how these constraints may be expressed mathematically.

\section{- Equality constraints}

Equality constraints refer to active power balance and reactive power balance. As shown in (17) and (18) there must be a balance between generated power and demand [28].

$$
\begin{gathered}
P_{g i}-P_{l i}-V_{i} \sum_{j=1}^{N_{b}} V_{j}\left(G_{i j} \cos \delta_{i j}+B_{i j} \sin \delta_{i j}\right)=0, \quad i \in N_{b} \\
Q_{g i}-Q_{l i}+Q_{o i}+Q_{c i}-V_{i} \sum_{i=1}^{N_{b}} V_{j}\left(G_{i j} \sin \delta_{i j}-B_{i j} \cos \delta_{i j}\right)=0, i \in N_{b}
\end{gathered}
$$

\section{- Inequality constraints}

\section{- Voltage constraints}

The bus voltage must be in the normal range between maximum and minimum value because too high or too low voltage magnitude may cause the problem.

$$
V_{i}^{\min } \leq V_{i} \leq V_{i}^{\max } \quad i \in N_{b}
$$

\section{- Generator reactive power limit}

The reactive power of the generator must be in the normal range in order to ensure that equipment is operating under design specifications.

$$
Q_{G i}^{\min } \leq Q_{g i} \leq Q_{G i}^{\max } \quad i \in N_{g}
$$

\section{- Active power generation limit}

Active power generated must be in the normal range

$$
P_{g}^{\min } \leq P_{g} \leq P_{g}^{\max } \quad i \in N_{g}
$$

\section{- Transmission line flow limit}

The apparent power which flows in transmission lines must be less than the maximum allowable limit in order to avoid any damage in transmission lines.

$$
\left|S_{l}\right| \leq S_{l}^{\max } \quad l \in N_{L}
$$

\section{- Transformer tap setting limit}

There is a difference in angle and magnitude of the voltage between terminals and to control this difference value of the tap position is changed. The limit of transformer tap setting is presented as:

$$
T_{K}^{\min } \leq T_{K} \leq T_{K}^{\max } \quad k \in N_{T}
$$

\section{- Reactive power generation limit of VAR source}

The new capacitor bank has a minimum and maximum limit and it is expressed as:

$$
Q_{C, i}^{\min } \leq Q_{C, i} \leq Q_{C, i}^{\max } \quad i \in N_{c a p}
$$

For SVC it must be in limit

$$
Q_{S V C, i}^{\min } \leq Q_{S V C, i} \leq Q_{S V C, i}^{\max } \quad i \in N_{S V C}
$$

The working range of TCSC must be chosen between -0.8 and 0.2 of the reactance of the installation line to avoid overcompensation.

$$
-0.8 X_{i j} \leq x_{T C S C i} \leq 0.2 X_{i j} \quad i \in N_{T C S C}
$$




\section{Proposed Solution Algorithm}

Because the RPP's objective functions and constraints are complicated, non-smooth, and non-differentiable, traditional methods fail to adequately address this issue [27]. MOGA and other evolutionary algorithms were used to overcome the drawbacks of traditional techniques. The GA is interested in natural genetics and natural selection search mechanisms [29].

The multi-objective optimization problem can be formulated as:

$$
\text { Minimizing, Maximizing } f_{i}(x, u) \quad i=1,2, \ldots \ldots N_{o b j}
$$

Subject to $\mathrm{g}(x, u)=0 \quad$ Equality constraints

$$
h(x, u) \leq 0 \quad \text { Inequality constraints }
$$

where, $f_{i}(x, u)$ is the objective function; $x$ is the set of the controllable variable; $u$ is the set of state variables.

The control variables $(\boldsymbol{x})$ can be defined as:

- Generator bus voltages magnitude which is continuous variables.

- Transformer tap positions are discrete variables.

- Size/location of capacitor banks are continuous/discrete variables.

- Size /location of FCATs devices are continuous/discrete variables.

- The state variables $(\boldsymbol{u})$ can be defined as:

- Voltage magnitude at load buses.

- Voltage phase angle at every bus.

- Power flows through the lines.

- Active power generation at a slack bus.

- Reactive power outputs from the generators.

In the present paper, the first objective is to minimize losses cost and the installed VAR sources cost,

$$
\text { Min } F_{1}=T V C_{V A R}+C_{l}
$$

And the second objective is to enhancement TTC

$$
\operatorname{Max} \quad F_{2}=P_{m}
$$

Two general approaches are utilized to address multipleobjective optimization problems. The different objective functions are first combined into a single composite function. The second method which used in this paper is to directly search for the complete Pareto optimum set [28]. The answer to the MOGA technique is a set of points on the Pareto's optimum front. The best compromise solution can be computed using a fuzzy min-max approach. The $i^{\text {th }}$ objective function $F_{i}$ is expressed using the fuzzy membership function $\lambda_{i}$, and is expressed as:

$$
\lambda_{i}=\left\{\begin{array}{lll}
1 & \text { if } & f_{i} \leq F_{i}^{\text {min }} \\
\frac{F_{i}^{\text {max }}-f_{i}}{F_{i}^{\text {max }}-F_{i}^{\text {min }}} & \text { if } & F_{i}^{\text {min }}<f_{i}<F_{i}^{\text {max }} \\
0 & \text { if } & f_{i} \geq F_{i}^{\text {min }}
\end{array}\right.
$$

Where, $F_{i}^{\max }$ and $F_{i}^{\min }$ are the maximum and minimum values of the $i^{\text {th }}$ objective function among all non-dominated solutions, respectively. For each non-dominated solution $\mathrm{M}$, the normalized membership function $\left(\lambda_{c}\right)$ is determined using:

$$
\lambda^{c}=\frac{\sum_{i=1}^{N_{o b j}} \lambda_{i}^{c}}{\sum_{c=1}^{M} \sum_{i=1}^{N_{o b j}} \lambda_{i}^{c}}
$$

The best compromise solution is the one having a maximum value of $\lambda^{c}$.

The proposed RPP algorithm based on MOGA is summarized in the following steps:

Step 1: Read the system data (bus, generator, branch, demand, etc...).

Step 2: Select the MOGA parameters: population size, number of generations, etc....

Step 3: Randomly initialize the population and set the generation count.

Step 4: Update system data according to RPP solving method and run power flow again.

Step 5: Run power flow

Step 6: Evaluate the objective functions and check the system constraints.

Step 7: Perform GA process selection, crossover, and mutation and generate the population for the next generation.

Step 8: Repeat the steps from 4 to 7 and increment the generation count until the count reaches the maximum number of generations.

Step 9: Apply the fuzzy min-max approach and select the optimal solution for this scenario from the Pareto solutions.

Step 10: If the stopping criteria are satisfied, stop and print the results.

\section{RESULTS AND DISCUSSION}

The proposed MOGA-based approach was applied to the IEEE 30-bus system. The single line diagram of IEEE-30 bus system is shown in Fig. 4. The network data are taken from [30]. The IEEE 30-bus system has six generators, 24 load buses, and 41 transmission lines, of which four branches (6$9),(6-10),(4-12)$, and (28-27) are with the tap changing transformer. The bus numbers $1,2,5,8,11$, and 13 are generator buses. The lower and upper limits for voltage magnitude of the load buses are 0.95 p.u. and 1.05 p.u. The transformer tapping is varied between 0.9 and 1.1 p.u. with the step size 0.025 . The capacitor banks have a rating between 0 and 5 MVAR with a step size of 1 MVAR. The SVC is varied between -100 and 100 MVAR and has a continuous control. The range of TCSC is between -0.8 and 0.2 of the reactance of the installation line. The system will be supported by eight new VAR sources [31]. 


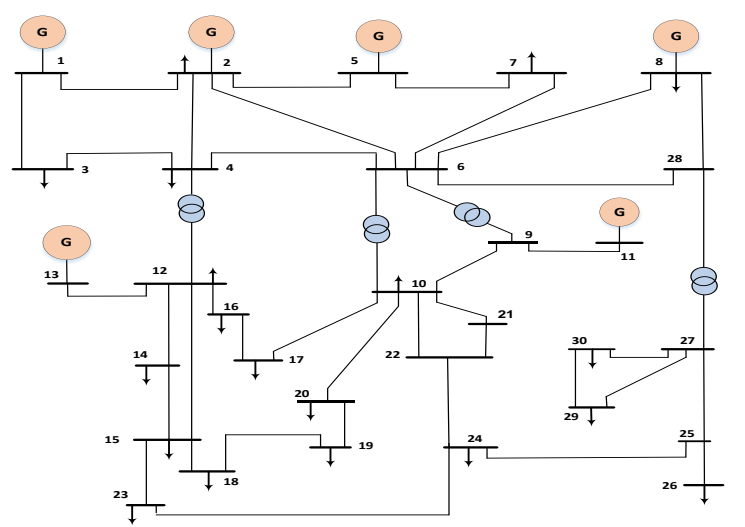

Fig. 4. IEEE-30 bus single line diagram.

Both objectives of minimizing the cost maximize TTC are applied first without and additional VAR sources but with changing the voltage setpoints of voltage-controlled buses and changing the setting of the tap of taps changing transformers, the results are presented in Table II.

The results illustrate three different cases: when minimizing the cost of losses is the objective function, when increasing TTC is the objective function, and finally when the objective function is a multi-objective. It shows that the loss cost is $2.511 \times 10^{6} \$$ for the first case, in the second case the TTC increases to be $475.29 \mathrm{MW}$ but with losses cost of $3.8 \times 10^{6} \$$. In the third case, it is noticed that the TTC increase to be 458.37 with $3.671 \times 10^{6} \$$ cost of losses.

Then, the different types of the new VAR source device are applied to solve the RPP problem when it is handled as a single objective and multi-objective problem and the values of control variables and results are shown.

TABLE II.

CONTROLLER SETTING BEFORE VAR SOURCES INSTALLING.

\begin{tabular}{l||l||l||l}
\multicolumn{1}{c||}{ ITEM } & BEST COST & BEST TTC & MULTI-OBJECTIVE \\
\hline$V_{G I}$ & 1.05 & 1.05 & 1.05 \\
\hline$V_{G 2}$ & 1.048 & 1.05 & 1.05 \\
\hline$V_{G 5}$ & 1.05 & 1.05 & 1.05 \\
\hline$V_{G S}$ & 1.05 & 1.014 & 1.029 \\
\hline$V_{G I I}$ & 1.05 & 1.028 & 1.05 \\
\hline$V_{G I 3}$ & 1.05 & 1.05 & 1.05 \\
\hline$T_{I}$ & 0.975 & 0.9 & 0.975 \\
\hline$T_{2}$ & 1.075 & 0.95 & 0.95 \\
\hline$T_{3}$ & 1.05 & 1.025 & 1 \\
\hline$T_{4}$ & 1.025 & 0.9 & 0.925 \\
\hline LOSSES $(M W)$ & 4.78 & 7.23 & 6.01 \\
\hline $\begin{array}{l}\text { COST OF } \\
\text { LOSSES }(\$)\end{array}$ & $2.511 \times 10^{6}$ & $3.8 \times 10^{6}$ & $3.671 \times 10^{6}$ \\
\hline TTC $(M W)$ & 283.4 & 475.29 & 458.37 \\
\hline $\begin{array}{l}\text { MIN VOLTAGE } \\
(P . U)\end{array}$ & $0.95(30)$ & $0.988(7)$ & $0.95(30)$ \\
\hline
\end{tabular}

To demonstrate the different types of the new VAR source device is applied to solve the RPP problem, three different cases have been considered:

Case 1: Minimizing the cost as a single objective case.

Case 2: Maximize the TTC of the power system as a single objective case.
Case 3: A multi-objective case of minimize losses and maximize TTC.

The values of control variables and the results of each case are shown below.

$>$ The case of minimizing the cost

There are three options which are either using capacitor bank, FACTS or a mixture between the two can be depended on to achieve the objective. A detailed view of the use of each type is handled in table III.

The overall cost was calculated by adding the costs of losses and additional VAR sources. From Table III it cleared that the total annual cost is $1.949 \times 10^{6}, 2.488 \times 10^{6}$, and $2.415 \times 10^{6}$ for capacitors, FACTS, and hybrid assortment, respectively. Due to the high cost of FACTS, it is noted that they obtain the highest cost in the table results. So, it should be emphasized that relying only on capacitors to compensate for a deficiency in reactive power results in the lowest feasible cost. On the contrary, relying on FACTS is extremely costly, and could mediate between the two by relying on a hybrid source of capacitors and FACTS. And overall, the total cost at the three options is still -of course- less than the cost of losses calculated before installing the new VAR sources where, the installation of new sources led to a significant reduction in the cost of losses, and this saving exceeded the cost of the new sources.

TABLE III.

CONTROLLER SETTING IN THE CASE OF MINIMIZING COST.

\begin{tabular}{|c|c|c|c|}
\hline ITEM & CAPACITORS & FACTS & HYBRID \\
\hline$V_{G I}$ & 1.05 & 1.05 & 1.05 \\
\hline$V_{G 2}$ & 1.049 & 1.05 & 1.05 \\
\hline$V_{G 5}$ & 1.05 & 1.05 & 1.05 \\
\hline$V_{G 8}$ & 1.05 & 1.05 & 1.05 \\
\hline$V_{G I I}$ & 1.05 & 1.05 & 1.05 \\
\hline$V_{G 13}$ & 1.05 & 1.05 & 1.05 \\
\hline$T_{1}$ & 0.95 & 0.975 & 1.1 \\
\hline$T_{2}$ & 1 & 1.05 & 1 \\
\hline$T_{3}$ & 1.075 & 1 & 1.075 \\
\hline$T_{4}$ & 1.05 & 1.1 & 0.975 \\
\hline$V A R_{1}$ & $2(16)$ & $8.6(5) \quad$ SVC & $13.2(24)$ SVC \\
\hline$V A R_{2}$ & $4(14)$ & $1.3(11) \mathrm{SVC}$ & $5.5(12) \quad$ SVC \\
\hline$V_{A R}$ & $4(4)$ & 1.6(24) SVC & $2(27)$ \\
\hline$V_{A A R}$ & 0 & 3.4 (29) SVC & 2(13) CAP \\
\hline$V A R_{5}$ & $3(1)$ & $\begin{array}{l}0.077(20) \\
\text { TCSC }\end{array}$ & $3(26) \quad$ CAP \\
\hline$V A R_{6}$ & $5(10)$ & $\begin{array}{l}0.002(29) \\
\text { TCSC }\end{array}$ & $\begin{array}{l}0.049(18) \\
\text { TCSC } \\
\end{array}$ \\
\hline$V_{A} R_{7}$ & $4(26)$ & $\begin{array}{l}0.023(8) \\
\text { TCSC }\end{array}$ & $\begin{array}{l}0.008(27) \\
\text { TCSC }\end{array}$ \\
\hline$V A R_{8}$ & 0 & $\begin{array}{l}0.02(40) \\
\text { TCSC } \\
\end{array}$ & $0.02(34)$ TCSC \\
\hline $\operatorname{LOSSES}(M W)$ & 3.5 & 3.67 & 3.83 \\
\hline $\begin{array}{l}\text { COST OF LOSSES } \\
(\$)\end{array}$ & $1.841 \times 10^{6}$ & $1.929 \times 10^{6}$ & $2.013 \times 10^{6}$ \\
\hline COST OF VAR (\$) & $1.084 \times 10^{5}$ & $5.594 \times 10^{5}$ & $4.017 \times 10^{5}$ \\
\hline $\begin{array}{l}\text { TOTAL ANNUAL } \\
\operatorname{COST}(\$) \\
\end{array}$ & $1.949 \times 10^{6}$ & $2.488 \times 10^{6}$ & $2.415 \times 10^{6}$ \\
\hline $\begin{array}{l}\text { MIN VOLTAGE } \\
(P . U)\end{array}$ & $0.95(30)$ & $0.95(26)$ & $0.95(24)$ \\
\hline
\end{tabular}


$>$ The case of maximizing the TTC

In this case, several controller variables have been derived in order to enhance the power transfer capability of power transactions between generators and loads in the IEEE 30 bus system while remaining within system limits. Results are shown in Table IV, which shows that the maximum value of TTC increases to be $497.735,559.006$, and 547.019 MW for three options of capacitors, FACTS, and hybrid assortment, respectively, compared to $475.29 \mathrm{MW}$ in the absence of additional VAR sources. Also, it is noticed that using FCATS achieved the highest value of the TTC, followed by the hybrid assortment, and then the capacitors.

\section{The multi-objectives case}

A multi-objective of minimizing total cost (losses cost \& investment cost) and maximize TTC is applied in this case. Results are shown in Table $\mathrm{V}$ and Fig. 5 shows the Pareto solutions for the problem in the three different options. The total annual cost is $2.02 \times 10^{6}, 2.65 \times 10^{6}$, and $2.486 \times 10^{6}$ for three options of capacitors, FACTS, and hybrid assortment, respectively where the TTC is 483.084, 539.055, and 529.986 respectively. It seems out that using the option of capacitor bank solely is more appropriate from a purely economic standpoint since it delivers the greatest potential net savings. However, it is not a superior choice for improving the TTC. While the adoption of FACTS devices is the greatest way to improve the TTC of the system, it comes with a significant expense. It also demonstrates that using a hybrid combination of capacitor banks and FACTS yields good results for improving TTC at a reasonable cost.

TABLE IV

CONTROLLER SETTING IN THE CASE OF MAXIMIZING TTC.

\begin{tabular}{|c|c|c|c|}
\hline ITEM & CAPACITORS & FACTS & HYBRID \\
\hline$V_{G I}$ & 1.05 & 1.05 & 1.05 \\
\hline$V_{G 2}$ & 1.05 & 1.05 & 1.05 \\
\hline$V_{G 5}$ & 1.05 & 1.05 & 1.02 \\
\hline$V_{G 8}$ & 1.026 & 1.02 & 1.03 \\
\hline$V_{G l l}$ & 1.05 & 1.02 & 1.05 \\
\hline$V_{G 13}$ & 1.019 & 1.05 & 1.01 \\
\hline$T_{1}$ & 0.975 & 1 & 1.075 \\
\hline$T_{2}$ & 0.95 & 0.975 & 0.95 \\
\hline$T_{3}$ & 0.975 & 1.1 & 1.025 \\
\hline$T_{4}$ & 0.95 & 0.9 & 0.925 \\
\hline$V A R_{I}$ & $4(29)$ & $28.3(24) \mathrm{SVC}$ & 48.74 (22) SVC \\
\hline$V A R_{2}$ & $3(13)$ & 98.46 (1) SVC & $10.48(26)$ SVC \\
\hline$V A R_{3}$ & $5(19)$ & 50.9(17) SVC & $5(18) \quad$ CAP \\
\hline$V A R_{4}$ & $5(25)$ & $2.87(30) \mathrm{SVC}$ & $\begin{array}{|ll|}5(17) & \text { CAP } \\
\end{array}$ \\
\hline$V^{\prime} R_{5}$ & $1(4)$ & 0.0115 (41) TCSC & $5(25) \quad$ CAP \\
\hline$V A R_{6}$ & $4(21)$ & 0.0744 (17) TCSC & 0.0927 (21) TCSC \\
\hline$V A R_{7}$ & $3(12)$ & 0.0197 (1) TCSC & $0.0427(22) \mathrm{TCSC}$ \\
\hline$V A R_{8}$ & $3(26)$ & $0.0122(29)$ TCSC & $0.0885(35)$ TCSC \\
\hline $\operatorname{LOSSES}(M W)$ & 6.91 & 8.8 & 8.45 \\
\hline COST OF LOSSES (\$) & $3.63 \times 10^{6}$ & $4.63 \times 10^{6}$ & $4.44 \times 10^{6}$ \\
\hline COST OF VAR (\$) & $1.38 \times 10^{5}$ & $3.97 \times 10^{6}$ & $1.38 \times 10^{6}$ \\
\hline $\begin{array}{l}\text { TOTAL ANNUAL } \\
\operatorname{COST}(\$)\end{array}$ & $3.768 \times 10^{6}$ & $8.59 \times 10^{6}$ & $5.82 \times 10^{6}$ \\
\hline$T T C(M W)$ & 497.735 & 559.006 & \begin{tabular}{|l|}
547.019 \\
\end{tabular} \\
\hline $\begin{array}{l}\text { MIN VOLTAGE } \\
(P . U)\end{array}$ & $0.997(7)$ & $0.95(7)$ & $0.95(9)$ \\
\hline
\end{tabular}

TABLE V

CONTROLLER SETTING IN THE CASE OF MULTI-OBJECTIVE.

\begin{tabular}{|c|c|c|c|}
\hline ITEM & CAPACITORS & FACTS & HYBRID \\
\hline$V_{G I}$ & 1.05 & 1.05 & 1.05 \\
\hline$V_{G 2}$ & 1.04 & 1.05 & 1.05 \\
\hline$V_{G S}$ & 1.01 & 1.05 & 0.99 \\
\hline$V_{G 8}$ & 1.02 & 1.04 & 0.99 \\
\hline$V_{G 11}$ & 1.05 & 1.05 & 1.05 \\
\hline$V_{G 13}$ & 1.05 & 1.03 & 1.05 \\
\hline$T_{1}$ & 0.95 & 1.075 & 0.95 \\
\hline$T_{2}$ & 1 & 0.95 & 0.9 \\
\hline$T_{3}$ & 1 & 1.075 & 1 \\
\hline$T_{4}$ & 0.95 & 0.925 & 0.925 \\
\hline$V A R_{I}$ & $2(26)$ & $3.71(17) \mathrm{SVC}$ & $3.4(12) \quad$ SVC \\
\hline$V A R_{2}$ & $3(21)$ & $22.2(24) \mathrm{SVC}$ & $22.01(24)$ SVC \\
\hline$V A R_{3}$ & $3(24)$ & $2.02(28) \mathrm{SVC}$ & $4(29)$ \\
\hline$V^{\prime} R_{4}$ & $1(20)$ & 15.77 (20) SVC & $1(30)$ \\
\hline$V A R_{5}$ & $2(18)$ & 0.0294 (34) TCSC & $1(18)$ \\
\hline$V A_{6}$ & $3(22)$ & 0.0001 (21) TCSC & $0.02(24) \quad$ TCSC \\
\hline$V^{\prime} R_{7}$ & $1(10)$ & 0.1107 (40) TCSC & $0.0988(17)$ TCSC \\
\hline$V A R_{8}$ & $2(16)$ & 0.0087 (36) TCSC & $0.03(25) \quad$ TCSC \\
\hline $\operatorname{LOSSES}(M W)$ & 3.69 & 3.51 & 3.67 \\
\hline COST OF LOSSES (\$) & $1.94 \times 10^{6}$ & $1.84 \times 10^{6}$ & $1.93 \times 10^{6}$ \\
\hline COST OF VAR (\$) & $8.43 \times 10^{4}$ & $8.1 \times 10^{5}$ & $5.56 \times 10^{5}$ \\
\hline $\begin{array}{l}\text { TOTAL ANNUAL } \\
\operatorname{COST}(\$)\end{array}$ & $2.02 \times 10^{6}$ & $2.65 \times 10^{6}$ & $2.486 \times 10^{6}$ \\
\hline $\operatorname{TTC}(M W)$ & 483.084 & \begin{tabular}{|l|}
539.055 \\
\end{tabular} & \begin{tabular}{|l|}
529.986 \\
\end{tabular} \\
\hline $\begin{array}{l}\text { MIN VOLTAGE } \\
(P . U)\end{array}$ & $0.988(30)$ & $.0975(7)$ & $0.969(7)$ \\
\hline
\end{tabular}

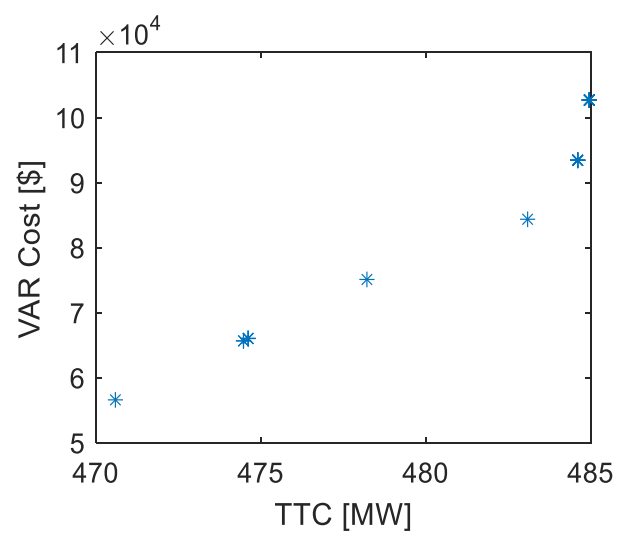

(a) Pareto solutions for capacitors option

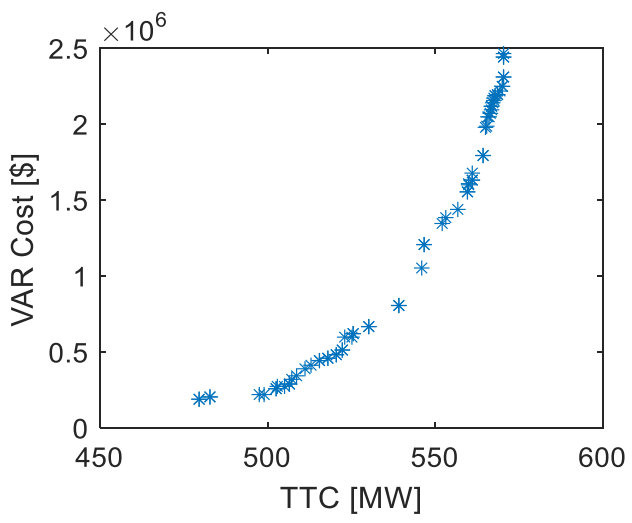

(b) Pareto solutions for FACTS option 


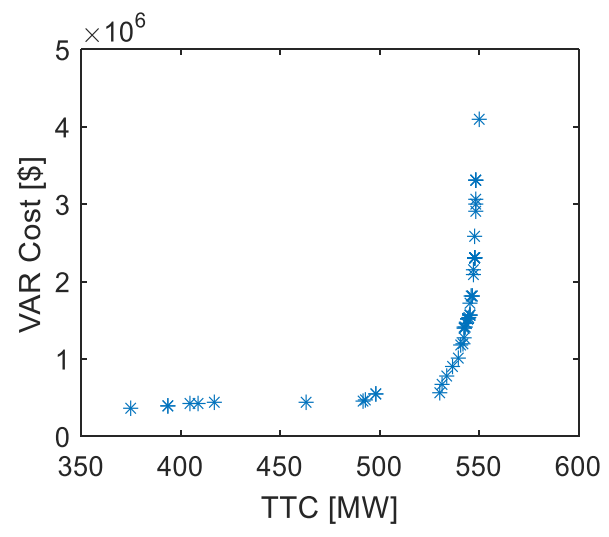

(c) Pareto solutions for a hybrid option

Fig. 5. Pareto solutions of multi-objective case.

\section{Conclusion}

A MOGA has been applied to solve the RPP problem with the objectives of minimizing the cost of losses and new VAR sources devices and enhancement system TTC. The proposed approach has been tested on the IEEE 30-bus test system. The solution relied on three available options, either using capacitors only or FACTS, or a mixture of the two. The results showed the effectiveness of the used solution method, as it is noted that the total cost is reduced and the TTC increases than its values before install the new VAR sources. It is also clear to us that the use of a mixture of capacitors and FACTS achieves good results for both goals, while the use of capacitors only reduces the cost more than it affects the increase in the TTC, and on the contrary, in the case of using FACTS, which leads to a significant increase in the TTC at the expense of cost.

\section{AUthors CONTRIBUTION}

\section{Mohammad I. Basha:}

He provides the design of work, data collection and tools, data analysis and interpretation, investigation, software, funding acquisition, resources and final approval of the version to be published.

\section{Abdelfattah A. Eladl:}

He participates in data collection and tools, project administration, software, methodology, drafting the article and final approval of the version to be published.

Azza A. ElDesouky:

She takes part in supervision, critical revision of the article, project administration, data collection and tools, methodology and drafting the article

\section{References}

[1] P. Rajkumar, "Application of particle swarm optimization technique for reactive power optimization problem," Ph.D. thesis, Dept. Elect. Eng., Anna Univ., Chennai, Aug. 2010.
[2] U.S.-Canada Power System Outage Task Force (2004, April). Final report on the August 14, 2003 blackout in the United States and Canada: causes and recommendations. Available at: https://www3.epa.gov/region1/npdes/merrimackstation/pdfs/ar/AR1165.pdf

[3] S. Chansareewittaya, P. Jirapong, "Power transfer capability enhancement with multitype FACTS controllers using hybrid particle swarm optimization," Electr. Eng., vol. 97, no. 2, pp. 119-127, Jun. 2015.

[4] K. Iba, H. Suzuki, K. Suzuki, K. Suzuki, "Practical reactive power allocation/operation planning using successive linear programming," IEEE Trans. Power Syst., vol. 3, no.2, pp. 558-566, May 1988.

[5] A. Ara, A. Kazemib, S. Gahramania, M. Behshada, "Optimal reactive power flow using multi-objective mathematical programming," Scientia Iranica, vol. 19, no. 6, pp. 1829-1836, Dec. 2012.

[6] H. Liu, L. Jin, J. McCalley, R. Kumar, V. Ajjarapu, N. Elia, "Planning reconfigurable reactive control for voltage stability limited power systems," IEEE Trans. Power Syst., vol. 24, no. 2, pp. 1029-1038, Jun. 2009.

[7] V. Gopalakrishnan, P. Thirunavukkarasu, R. Prasanna, "Reactive Power planning using hybrid evolutionary programming method," in Proc. IEEE PES, New York, N.Y., USA, Oct. 10-13, 2004.

[8] B. Bhattacharyya, S. Raj, "PSO based bio inspired algorithms for reactive power planning," Int. J Electr. Power Energy Syst., vol. 74, pp. 396-402, Jan. 2016.

[9] A. Shaheen, R. El-Sehiemy, S. Farrag, "A novel adequate bi-level reactive power planning strategy," Int. J Electr. Power Energy Syst., vol. 78, pp. 879-909, Jun. 2016

[10] A. Shaheen, R. El-Sehiemy, S. Farrag, "A reactive power planning procedure considering iterative identification of VAR candidate buses," Neural Comput. Appl., vol. 31, no. 3, pp. 653-674, Mar. 2019.

[11] A. Abou El-Ela, A. Kinawy, R. El-Sehiemy, M. Mouwafi, "Optimal reactive power dispatch using ant colony optimization algorithm", Electr. Eng., vol. 93, pp. 103-16, Jan. 2011.

[12] B. Bhattacharyya, S. Kumar, "Reactive power planning with FACTS devices using gravitational search algorithm," Ain Shams Eng. J, vol. 6, no. 3, pp. 865-871, Sep. 2015.

[13] A. Gupta, A. Gupta, A. Kaushal, A. Chaubey, A. Sharma, "Reactive Power Planning using Swarm Evolutionary Techniques," in Proc. - IEEE 2020 2nd Int. Conf. Adv. Comput. Commun. Control Networking, ICACCCN 2020, Greater Noida, India, Dec. 18-19, 2020.

[14] Y. Muhammad, R. Akhtar, R. Khan, F. Ullah, M. Raja, J. Machado, "Design of fractional evolutionary processing for reactive power planning with FACTS devices," Sci. Rep., vol. 11, no. 1, pp. 1-29, Jan. 2021.

[15] G. MadhusudhanaRao, P. Vijaya Ramarao, T. Jayanth kumar, "Optimal Location of TCSC and SVC for Enhancement of ATC in a De-Regulated Environment using RGA," in IEEE Inter. Conf. on Computational Intelligence and Computing Research, Coimbatore, India, Dec. 28-29, 2010.

[16] D. Menniti, N. Scordino, N.Sorrentino, "A new method for SSSC optimal location to improve power system Available Transfer Capability", in Proc. IEEE PES, Atlanta, GA, USA, Oct. 29- Nov. 1, 2004.

[17] W. Ongsakul, P. Jirapong, "Optimal Allocation of FACTS Devices to Enhance Total Transfer Capability Using Evolutionary Programming," in IEEE Inter. Symposium on Circuits and Systems, Kobe, Japan, May 23-26, 2005.

[18] T. Nireekshana, G. K. Rao, S. S. Raju, "Available transfer capability enhancement with FACTS using Cat Swarm Optimization," Ain Shams Eng. J, vol. 7, no. 1, pp. 159-167, Mar. 2015.

[19] S. Chansareewittaya, "Optimal Power Flow for Enhance TTC with Optimal Number of SVC by using Improved Hybrid TSSA", ECTI-CIT, vol. 13, no. 1, pp. 37-48, May 2019.

[20] B. Adewolu, A. Saha, "Contingency Control Capability of an Optimized HVDC-Based VSC Transmission System", in 2020 International SAUPEC/RobMech/PRASA Conference, Cape Town, South Africa, Jan. 29-31, 2020.

[21] A. Elmitwally, A. Eladl, "Planning of multi-type FACTS devices in restructured power systems with wind generation," Int. J Electr. Power Energy Syst., vol. 77, pp. 33-42, May 2016.

[22] J. Dixon, L. Morán, J. Rodríguez, R. Domke, "Reactive Power Compensation Technologies: State-of-the-Art Reviewn," Proceedings of the IEEE, vol. 93, no. 12, pp. 2144-2164, Dec. 2005. 
[23] N. Abdullah, I. Musirin, M. Othman, "Static VAR Compensator for Minimizing Transmission Loss and Installation Cost Calculation," Australian J of Basic and Applied Sciences, vol. 4, no. 4, pp. 646-657, Apr. 2010.

[24] A. Mohanty, A. Barik, "Power System Stability Improvement Using FACTS Devices," Inter. J of Modern Eng. Research, vol. 1, no. 2, pp. 666-672, Aug. 2011.

[25] S. Jumaat, I. Musirin, M. Othman, H. Mokhlis, "Particle Swarm Optimization Techniques for Optimal Location and Sizing of Thyristor Controlled Series Capacitor," in Inter. Conf. on Innovation, Management and Technology Research, Malacca, Malaysia, May 21-22, 2012.

[26] M. Esmaili, H. Shayanfar, R. Moslemi, "Locating series FACTS devices for multi-objective congestion management improving voltage and transient stability," European Journal of Operational Research, vol. 236, no. 2, pp.763-773, Jul. 2014.

[27] S. Ramesh, S. Kannan, S. Baskar, "Application of modified NSGA-II Algorithm to multi-objective reactive power planning," Appl. Soft Comput., vol. 12, pp. 741-753, Feb. 2012.

[28] A. Shaheen, S. Spea, S. Farrag, M. Abido. "A review of meta-heuristic algorithms for reactive power planning problem," Ain Shams Eng. J, vol. 9, no. 2, pp. 215-231, Jun. 2018.

[29] K. Lee, F. Yang, "Optimal reactive power planning using evolutionary algorithms: a comparative study for evolutionary programming, evolutionary strategy, genetic algorithm, and linear programming," IEEE Trans. Power Syst., vol. 13, no. 1, pp. 101-108, Feb. 1998.

[30] O. Alsac, B. Stott, "optimal load flow with steady-state security," IEEE Trans. Power Syst., vol. 93, no. 3, pp.745-751, May. 1974.

[31] M. Saravanan, S. Slochanal, P. Venkatesh, J. Abraham," Application of particle swarm optimization technique for optimal location of FACTS devices considering cost of installation and system loadability," Elec. Power Sys. Research, vol. 77, no. 3-4, pp. 276-283, Mar. 2007.

\section{Title Arabic:}

$$
\text { تخطيط الطاقة غير الفعالة وتحسين قدرة النقل باستخدام الأجهزة المرنة }
$$

\section{Arabic Abstract:}

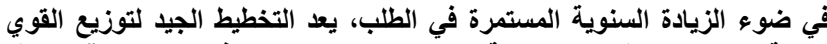

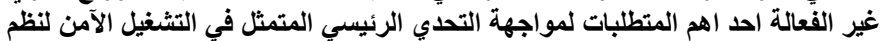

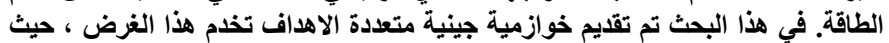

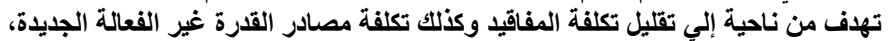

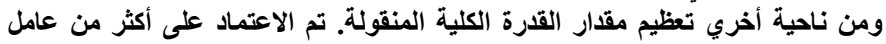

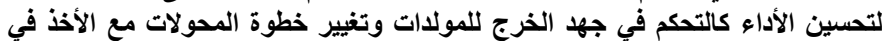

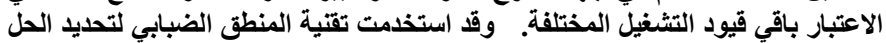

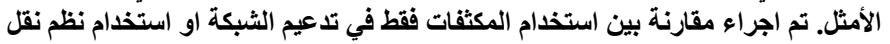

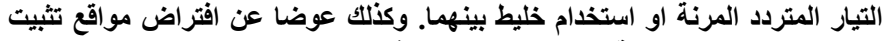

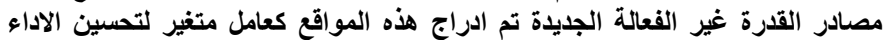

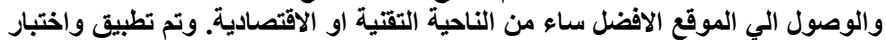

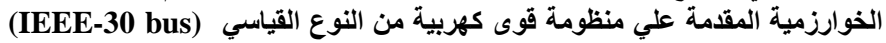

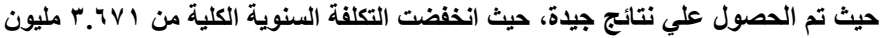

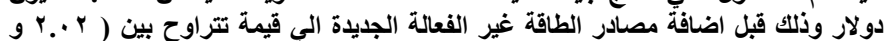

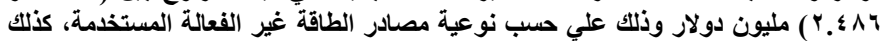

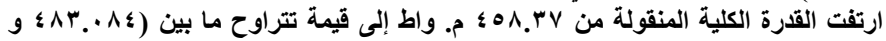

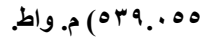

